\title{
Embelin as a Potential Drug Molecule: A Review
}

\section{Sakesh Kumar ${ }^{*}$ and Rahul Deshmukh}

ISF College of Pharmacy, Moga, Punjab, India

"Corresponding author: Sakesh Kumar, ISF College of Pharmacy, Moga, Punjab, India, Tel: +91-8699059541; E-mail: sgprem92@gmail.com

Received date: Oct 17, 2017; Accepted date: Dec 05, 2017; Published date: Dec 11, 2017

Copyright: (c) 2017 Kumar S, et al. This is an open-access article distributed under the terms of the Creative Commons Attribution License, which permits unrestricted use, distribution and reproduction in any medium, provided the original author and source are credited.

\section{Abstract}

Embelia ribes are traditionally used medicinal remedies in India. Embelin is a hydroxyl benzoquinone with alkyl substitution and is considered as one of the main constituents. Embelin has various biological activities includes anticonvulsant, antidepressant, antidiabetic, antifertility, antitumor etc. This review is an overall overview of the existing pharmacology of $E$. ribes, helping to fuel further research in the various unexplored activities that are attributable to this plant.
\end{abstract}

Keywords: Embelia ribes; Embelin; Hydroxyl benzoquinone; Anticonvulsant; Antidiabetic; Antifertility; Antitumor

\section{Introduction}

Berries of Embelia ribes are used for various traditional medicinal remedies in India. Embelin is a natural hydroxy benzoquinone with alkyl substitution and is considered as one of the main constituents of plant Embelia ribes (family: Myrsinaceae) [1,2]. Embelin is known to possess various biological activities which mainly include anxiolytic, anticonvulsant, antidepressant, antidiabetic, wound healing, anthelmintic, antimicrobial, antitumor, chemopreventive, antioxidant, antifertility etc. It has also found a valuable role in different diseases like Huntington disease, myocardial infarction, acute respiratory distress syndrome and ulcerative colitis.

Embelia ribes Burm., a plant of climber in nature, which belongs to the Myrsinaceae family. A large, scandent climber with long slender, flexible, terete branches; bark studded with lenticels. Leaves are simple, alternate, elliptic-lanceolate, gland-dotted, short and obtusely acuminate, entire, shiny above. Flowers are small, white or greenish, in both terminal and axillary panicles. Fruits are globose, wrinkled or warty, dull red to nearly black, a short pedicel often present usually one-seeded and globose (Figure 1).

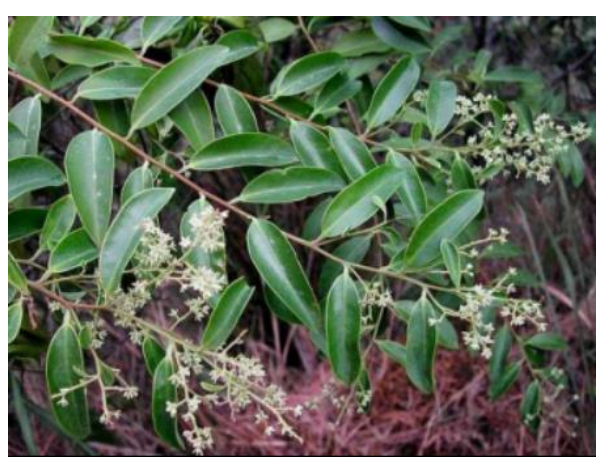

Figure 1: Picture of Embelia ribes.
The main parts of plants used include fruits (berries), roots and leaf, to cure various diseases. Chemically, embelin is $\mathrm{C}_{17} \mathrm{H}_{26} \mathrm{O}_{4}$ and is written as 2, 5-dihydroxy-3-undecylcyclohexa-2, 5-diene-1, 4-dione according to IUPAC nomenclature. It has molecular weight equivalent to $294.38594 \mathrm{~g} / \mathrm{mol}$ (Figure 2).

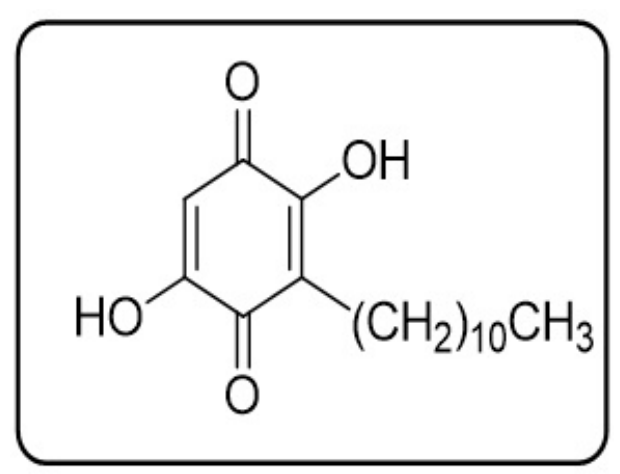

Figure 2: Chemical structure of Embelin.

\section{Biological activities}

Embelin as anxiolytic: Among various psychiatric disorders, anxiety is one of the most common disorder [3,4]. It constitutes a considerable public health burden. Recent epidemiological evidence suggests that it is much more widespread than traditional belief, influencing up to half of the general population [5]. Gupta et al. described that embelin expressed significant activity in light and dark model, elevated plus maze and open field test induced anxiety models, thereby proving its anxiolytic potential in Figure 3. 


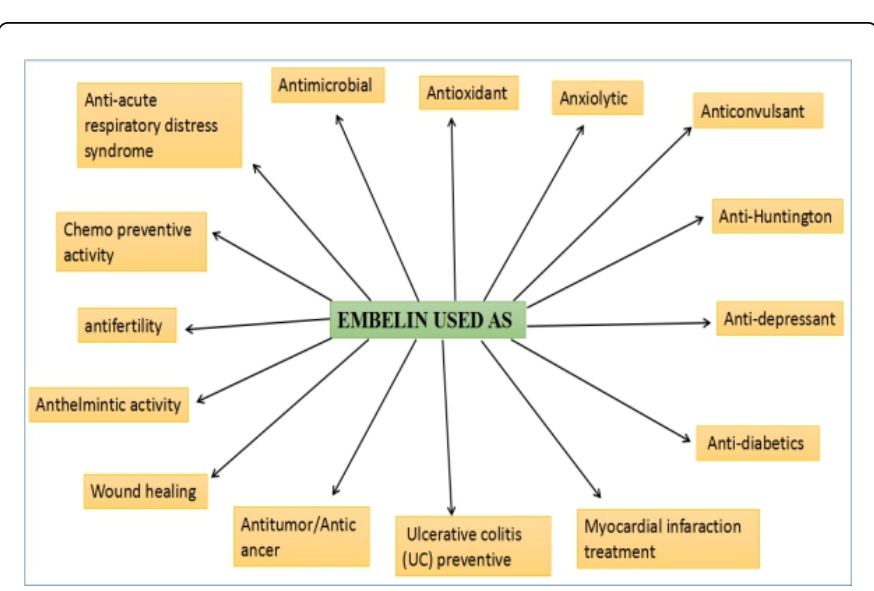

Figure 3: Biological Activities of Embelin.

\section{Anticonvulsant activity}

The prevalence of epilepsy in developed countries is about 50 per 100,000 while that of developing countries is 100 per 100,000 . Currently available antiepileptic drugs are synthetic molecules related with numerous side effects and about $30 \%$ of the patients continue to have seizures with this treatment [6,7]. Safety against Hind Limb Tonic Extension (HLTE) in MES (Maximal Electro Shock) predicts the potential of a sample to check the spread of seizure release from the epileptic focus in brain and suppressing generalized tonic-clonic and partial seizures [8]. The dose dependent blockage of HLTE, decrease in the time taken for stupor, a complete eradication of extension and fast onset of stupor has been observed by embelin which indicates its antiepileptic activity. Embelin has also been found to exhibit significant and dose dependent delayed onset of clonic-tonic actions and protection from PTZ induced mortality. However, it may be interfering with GABAergic mechanism to exert its anticonvulsant effect [9].

\section{Effect of embelin against acute respiratory distress syndrome}

Pulmonary neutrophilia is a firm finding in human Adult Respiratory Distress Syndrome (ARDS) and in Chronic Obstructive Pulmonary Disease (COPD) which is mainly distinguished by airway hyper-reactivity, poorly reversible airflow obstruction, presence of pulmonary fibrosis, mucus hyper secretion, tachypnea and dyspnea on exertion [10,11]. Lipopolysaccharide (LPS) is a cell wall constituent of gram-negative bacteria which is ubiquitous in the environment and is commonly used to set up the experimental model of ARDS [12,13]. LPS administration through intratracheal to rats leads to an increase in pulmonary vascular permeability leading to neutrophil migration into the air spaces [14]. In spite of advancement in treatment approaches ARDS is still integrated with substantial mortality with an approximates ranging from $26 \%$ to $58 \%[15,16]$. Consequently, the need remains for medications that are safer and equally or more effective. The present study revealed that pre-treatment with embelin significantly attenuated LPS-induced acute respiratory distress syndrome in rats, which is possibly linked with inhibition of albumin, protein level, MPO activity and inflammatory cell recruitment in BAL fluid. In addition embelin also prevented TNF, NO over production and improved lung histology decreasing infiltration of inflammatory cells. The protective effect might be related with the inhibition of overproduction of pro-inflammatory mediators. These experimental results suggest that embelin is a potential therapeutic antiinflammatory compound for ARDS therapy.

\section{Role of embelin in Huntington's disease (HD)}

Huntington's disease is a progressive neurological disorder which is mainly characterized by clinical triad movement disorder, dementia and psychiatric disturbance due to striatal-specific neuronal degeneration $[17,18]$. Although the exact cause of neuronal death in $\mathrm{HD}$ remains unknown, it has been postulated that the abnormal aggregation of the mutant huntingtin protein may cause toxic effects in neurons leading to a cascade of pathogenic mechanisms associated with transcriptional dysfunction, oxidative stress, mitochondrial alterations, apoptosis, bioenergetic defects and subsequent excitotoxicity [19]. HD patients often exhibit deficits in executive tasks which mainly require planning, cognitive flexibility and problem solving. HD possesses challenges for health and social care professionals due to its complexity and unpredictability. With an incidence of 2-10 per 100,000, HD afflicts 30,000 people in USA and another 250, 000 persons are genetically at risk [18].

Several animal models exists for HD such as stereotactic injection of kainic, quinolinic and ibotenic acids into specific region of the brain, but systemic administration of 3-nitropropionic acid (3-NP) is the recent and most popularly used [20,21]. 3-NP crosses the blood-brain barrier and at cellular level it is an irreversible inhibitor of the electron transport enzyme succinate dehydrogenase (SDH). It is a mitochondrial complex II enzyme responsible for the oxidation of succinate to fumarate in Kreb's cycle. Subsequently it blocks the transport of electrons in oxidative phosphorylation causing decreased ATP levels in brain. It affects normal brain electrical activity and oxidative stress has been suggested to play a role in 3-NP toxicity. Neurons are considered to be highly active metabolically and therefore processes that affect the mitochondrial function invariably leads to neuronal death $[22,23]$. Thus, a major factor involving 3-NP toxicity could be mainly because of cellular and mitochondrial stress [24]. Accumulating data indicates that 3 -NP produces free radicals and consequent disturbance of glutathione redox cycle [25]. The inflammation associated with 3-NP, also acts as a contributing factor for neuronal damage and further free radical generation [23]. In addition to striatum which is the major site of toxicity, 3-NP also causes severe damage to the neurons present in other regions of brain like hippocampus, cortex and hypothalamus [26]. Dhadde et al. demonstrated that embelin normalized the altered behavioral, biochemical and histopathological parameters in 3-NP treated rats, suggesting its neuroprotective efficacy. The possible mode of protection may be due its antioxidant properties. However, further research is warranted to elucidate the specific mechanisms involved.

\section{Anti-depressant action of embelin}

According to WHO, 1999, Depression is a common disorder that is projected to become the second biggest contributor to the global health problem and disability by the year 2020. There is now an ever increasing rate of depression-related death both by suicide and due to the associated physical/physiological disorders [27]. The primary symptoms of depression are unhappiness, low mood or reduced interest. Most of the today's antidepressant therapies have limitations due to either their inadequate efficacy over prolonged usage or unwanted side effects. 
Page 3 of 7

The major bioactive constituent of Embelia ribes is embelin, was found to possess significant activity in mice TST and FST experimental models. The observed potent activity at doses lower than the standard antidepressant drug, imipramine, suggests the potential of embelin and Embelia ribes for treating mental depression. Future studies are required to ascertain the exact mechanism (s) of action of embelin's antidepressant-like effects.

\section{Anti-diabetic potential}

Diabetes is a major endocrine disorder causing morbidity and mortality worldwide. The problem of diabetes is mostly prominent to India, as several studies have clearly documented an increased ethnic susceptibility to diabetes in migrant Asian Indians [28,29]. Recent epidemiological studies have pointed to the growing epidemic of diabetes in India [30]. Indeed, according to the recent Diabetes Atlas produced by the International Diabetes Federation (IDF), India is home to the largest number of people with diabetes in the world, 40.9 million diabetic subjects in 2007 and these numbers are predicted to increase to 69.9 million by 2025 [31]. Diabetes mellitus is a heterogeneous group of disorders characterized by chronic hyperglycemia, polyurea, polydipsia, polyphagia, emaciation and weakness due to disturbance in carbohydrate, fat and protein metabolism and directly related to absolute or relative deficiency in insulin secretion and/or insulin action [32,33]. Diabetes is fast turning out to be the epidemic of the 21st century. Type 2 Diabetes Mellitus (T2DM), non-insulin dependent diabetes, is more prevalent (more than $90 \%$ of all diabetes cases) and the main driver of the diabetes epidemic, now affects $5.9 \%$ of the world's adult population in developing countries [34].

Diabetes is induced by various models in rats to study the effect of embelin. The models which are used to induce diabetes are alloxane induced diabetes, streptozotocin-induced diabetes, lithium-induced nephrogenic diabetes insipidus. It is a type of diabetes insipidus, manifested by a lack of response of the collecting duct to circulating Anti-Diuretic Hormone (ADH) and cause frequent and excessive urination.

The present study demonstrated that the treatment of diabetic rats with embelin have exerted a considerable hypoglycemic effect. In addition, embelin could ameliorate the impaired renal function, inhibition of liver damage and resemble of islets of pancreas associated with alloxan diabetes. It is an ideal lead molecule for further antidiabetic drug development due to its safety and efficacy. It has also been found that embelin treatment reduced the elevated plasma glucose, lipid profile, ameliorated oxidative stress and inhibited intracellular pro inflammatory mediators in HFD+STZ induced diabetic rats. Moreover, further results indicate that pro-inflammatory mediators and oxidative stress may be major triggering factors in type 2 diabetes mellitus. The therapeutic properties of embelin may be useful as bio-modulator or adjuvant and can be combined with clinically effective anti-diabetic agents. With the use of such adjuvants in clinical medicine, some of the side effects observed on chronic treatment of anti-diabetic drugs can be markedly reduce. Ethanolic extract of E. ribes has potential for its evaluation as a protective agent against toxicity induced by streptozotocin.

Embelin exhibited insulin sensitizing effect through adipose tissue specific partial agonism of PPAR $\gamma$ and activated glucose transport through translocation and activation of GLUT4 mediated by insulin dependent PI3k/p-Akt pathway in epididymal adipose tissue. It also protected $\beta$-cells by scavenging free radicals and alleviated dyslipidemia in insulin resistant animal model. This drug can be considered useful in the prevention and treatment of obesity related T2DM. However, it seemed to be effective in NDI by its predominant effect on promoting antioxidant status and decrease the urine excretion may be due to the blocking of sodium channels.

\section{Ulcerative colitis (UC)}

Inflammatory bowel diseases (IBD), Crohn's disease and Ulcerative Colitis (UC) are chronic, relapsing, remitting gastrointestinal (GI) diseases characterized by chronic inflammation of the intestine [35-38]. UC and Crohn's disease are associated with intestinal and extra intestinal clinical manifestations of disease, which include weight loss, diarrhea accompanied by blood and/or mucus, fever, gastric dysmotility and shortening of the colon $[39,40]$. The pathogenesis of IBD remains unclear, but is mainly related to the imbalances between various pro-inflammatory cytokines such as, tumor necrosis factor (TNF- $\alpha$ ), interferongamma (IFN- $\gamma$ ), interleukin-1 (IL-1), IL-6 and IL-12 and anti-inflammatory cytokines, such as IL-4, IL-10, IL-11, are believed to play a central role in modulating inflammation [41]. Experimental colitis was induced by giving mice drinking water ad libitum containing 5\% (w/v) DSS for 7 days. Results of this study suggested the potent anti-inflammatory effects of embelin in DSSinduced colitis model. It is mediated via the inhibition of proinflammatory mediator production. Furthermore, embelin was found to have better therapeutic effects than 5-ASA, which is currently used to treat IBD. However, further studies are required to elucidate the mechanism responsible for therapeutic effects of embelin.

\section{Wound healing activity}

Healing of wound is a complex cellular event by which injured tissue repaired as steadily as possible to its normal stage. The healing process depends upon the curable abilities of the tissue, the type and degree of injury and natural environment of health of the tissue [42]. It is a physiological feedback to the tissue injury that results in the restoration of injured tissue by living tissue and thus restoration of tissue integrity. Wound repair mechanism occurs by four basic processes such as inflammation, wound contraction, epithelialization and granulation tissue formation. Inflammation outset promptly after the interruption of tissue integrity. The platelets became adherent with clotting factors and form haemostatic plug to prevent bleeding from the vessels. The prostaglandins (PGE1 and PGE2) are discharged in the inflammatory area and suggest to be the final mediators of acute inflammation and may play a haemostatic role for leukocytes and fibroblasts. The active ambulatory leukocytes migrate into the wound and start engulfing cellular debris, at the introductory stages contraction of wound begin slowly and turn into speedy after 3 to 4 days. The myofibroblasts which is present in the margin of wound, emerge to establish the machinery for the wound contraction. These are liable for overlaying debris. The epithelialization of wound is mostly carried out by proliferating and migrating marginal basal cells which are lying close to the wound margin. The hematoma present inside the wound can be replaced by granulation tissue consisting of new capillaries and fibroblasts. The fibroblasts are most likely responsible for production of the mucopolysaccharide ground substance. The lymphatics develop new nerve fibres along with the formation of scar tissue in which collagen turn over increases. The ethanolic extract of Embelia ribes tends to augment the formation of collagen fibres. At last, the breaking strength of the wound increases according to the increase of collagen content. Morton and Malone 
Page 4 of 7

explained wound closure and time of epithelialization in a way that rats were inflicted with excision wound [43] under light ether anesthesia. The skin of the impressed area was excised to full thickness on the dorsal thoracic region of the rats to obtain a wound area of about $500 \mathrm{~mm}^{2}$. The drugs were applied topically on a daily basis till the complete epithelialisation has resulted. The wound closure was calculated at regular intervals to see the percentage of wound closure and epithelialization time. The results indicated the formation of new epithelial tissue which was covering the wound. The period of epithelialisation was given by the number of days required for deteriorating of the scar without any residual of the raw wound. Ehrlich and Hunt described incision wound model [44] consisting of 6 $\mathrm{cm}$ long paravertebral incisions which were made through full thickness of the skin on either side of the vertebral column of the rat. The incision was carefully done with at least $1 \mathrm{~cm}$ lateral to vertebral column. The wounds were left undressed and drugs were applied topically to the wound once a day, till complete healing had resulted. The skin breaking strength of the 10-day-old wound was measured by continuous constant water technique as explained by Lee and Tong. The skin breaking strength is expressed as the minimum weight (in grams) of water required to bring about the gapping of the wound. Significant wound healing activity was most commonly observed in animals treated with ethanolic extract and embelin. The histology of granulation tissue for animals treated with embelin revealed complete healing with more of fibroblasts within marked increase of collagen tissue and increased number of blood vessels.

\section{Anthelmintic activity}

Helminthes infections is one of the most widespread infections in humans, covering a huge population around the world. Although the majority of infections caused due to helminthes are generally restricted to tropical regions and results in enormous health hazard contributing to the prevalence of undernourishment, anemia, eosinophilia and pneumonia among various individuals $[45,46]$. Parasitic diseases affects population prominently in endemic areas causing brutal morbidity [47]. The foremost problem in treatment of helminthes diseases is that the gastro-intestinal helminthes generally becomes resistant to currently available anthelmintic drugs [48].

Anthelmintics are basically the drugs that tend to eliminate parasitic worms (helminths) from the body, by either inhibiting or killing them. They are also referred as vermifuges or vermicides [49]. Honiberger [50] along with other scientist described Embelia ribes as an essential vermifuge. Watt [51] explained the additional power of powdered seeds (E. ribes) in curdled milk in combination with castor oil which tends to fasten the eradication/expel of tapeworms. According to Ved Prakash and Mehrotra [52], E. ribes is considered as one of the important herbs among the fifty-two Indian traditional herbs responsible for anthelmintic activity. Furthermore, herbal monographs (of $\mathrm{M} / \mathrm{s}$ Himalayan Drugs Company, Bengaluru) suggested that embelin is primarily effective against tapeworm and not roundworm or hookworm. The nematocidal activity of embelin has been explained by Mojumder and Mishra [53-56] against root-knot nematode (Meloidogyne incognita) with $90 \%$ mortality after exposure for $48 \mathrm{~h}$ (at $100 \mathrm{ppm}$ concentration level). E. ribes seed oil demonstrated effective activity against Pheretima posthuma compared to standard piperazine citrate $(10 \mathrm{mg} / \mathrm{ml})$ was reported by Jalalpure et al.

\section{Antimicrobial activity}

Anti-microbial is a compound that either kills or inhibits the growth of microbes such as bacteria, fungi, or protozoans. Chitra et al. studied antimicrobial activity of embelin against 12 pathogenic bacteria using disk diffusion method. It was observed that inhibition occurred for all the twelve at a concentration of 100 microgram/disk, but two of the bacterium namely $E$. coli and $K$. pneumoniae revealed significant level of inhibition. Embelin inhibition against methicillin-sensitive and methicillin-resistant strains of Staphylococcus aureus with minimal inhibitory concentration (MIC) value of $250,62 \mu \mathrm{g} / \mathrm{ml}$ respectively has also been reported by Feresin et al. [57]. It was also examined against E. coli which was found to have MIC value of $50 \mu \mathrm{g} / \mathrm{ml}$. Embelin has also been reported to inhibit various dermatophytes namely Epidermophyton floccosum, Microsporum canis, Trichophyton mentagrophytes and Trichophyton rubrum with MIC of $50 \mu \mathrm{g} / \mathrm{ml}$, however $100 \mu \mathrm{g} / \mathrm{ml}$ was observed against Microsporum gypseum. Rani and Khullar [57] explained the moderate antibacterial activity of aqueous and methanol extracts of E. ribes. Tambekar et al. [58] reported that acetone fraction of $E$. ribes berries possessed mild antibacterial property against Enterobacter aerogenes, Klebsiella pnemoniae, compared to the standard drug Amoxicillin. Rathi et al. [59] examined petroleum ether extract of $E$. ribes which had lowest MIC value of $250 \mu \mathrm{g} / \mathrm{ml}$ against Candida parapsilosis (MTCC 1744) and $360 \mu \mathrm{g} / \mathrm{ml}$ against Candida laurintis (MTCC 2898) while water extract of E. ribes had higher MIC value for all organisms. Suthar et al. [60] reported embelin with antifungal potential against Aspergillus flavus 871 and Aspergillus fumigates 2550 with MIC50 values of 470, $1015 \mathrm{mg} / \mathrm{L}$ respectively. In our study, we observed bactericidal activity of embelin against gram positive organisms and bacteriostatic activity against gram negative organism [61].

\section{Antitumor activity}

Antitumor/anticancer activity compounds are drug or agent that inhibit, delay or reverse tumor. Chitra et al. [62] attempted to describe antitumor activity of embelin in methylcholanthrene-induced fibrosarcoma in albino rats along with their enhanced survival time. Nikolovska-Coleska et al. [63] reported embelin as a fairly potent, nonpeptidic, cell-permeable, small-molecule inhibitor of XIAP. It represents a promising lead compound for entirely new class of anticancer agents that target the BIR3 domain of XIAP. Dai et al. [64] explained the embelin potential to inhibit chemical carcinogeninduced colon carcinogenesis.

\section{Chemopreventive activity}

The uses of a drug or compound which tend to interfere with a disease process are called chemopreventive agents. Sreepriya and Bali [65] revealed that embelin prevents the induction of hepatic hyper plastic nodules, bodyweight loss, increase in the levels of hepatic diagnostic markers and hypoproteinemia against DENA/PB-induced hepato-carcinogenesis in wistar rats.

\section{Antioxidant activity}

An antioxidant is a molecule or agent capable of inhibiting the oxidation of molecules. Oxidation reactions generate free radicals which trigger the biochemical chain reactions and finally damaging cells. Antioxidants tend to terminate these chain reactions by neutralizing free radical intermediates and also inhibiting other oxidation reactions. Both plants and animals owns complex systems of 
multiple types of antioxidants defense systems endogenously, such as glutathione, vitamin $\mathrm{C}$ and vitamin $\mathrm{E}$ (classical examples of nonenzymatic antioxidants) and catalase, superoxide dismutase and various peroxidases (enzymatic antioxidants). With regard to antioxidant activity of embelin few reports are available in public domain. Sumino et al. [66] reported that embelin exhibited free radical scavenging activities towards diphenyl-picrylhydrazyl (DPPH) radicals inhibitory concentration (IC50) of $23.3 \pm 0.5 \mu \mathrm{M}$. Joshi et al. [67] explained the inhibition of lipid peroxidation and restoration of impaired Mn-superoxide dismutase in rat liver mitochondria by embelin. Siddharthan Surveswaran et al. [68] illusteated crude E. ribes displaying free radical scavenging activities when tested using DiPhenyl-2-picryl Hydrazyl (DPPH). Uma et al. [69] described antioxidant activity against streptozotocin induced diabetic rats using aqueous extract of $E$. ribes administered orally (100 and $200 \mathrm{mg} / \mathrm{kg}$ body weight) and whereas Venkateshwar rao et al. [70-79] substantiates the antioxidant activity of embelin. Dharmendra Singh et al. reported antioxidant activity of embelin against hepatotoxicity induced rats (at concentration of $25 \mathrm{mg} / \mathrm{kg}$ body weight). Radhakrishnan et al. [72] observed embelin lipid peroxide inhibition and restoration of impaired Superoxide dismutase in UV B-induced lymphocytes and fibroblasts by embelin.

\section{Conclusion}

Conclusively, embelin is an efficient drug molecule with a potential to act against different diseases. It has widespread biological activities such as antioxidant, anticancer, antimicrobial and has minimum side effects. Thus, embelin can be considered as potential drug molecule as well as adjuvant for various biological implications and thereby serving the human society.

\section{Acknowledgement}

Authors are thankful to Mr. Parveen Garg, the chairman and Dr. Rahul Deshmukh, HOD Pharmacology, ISF College of Pharmacy, Moga (Punjab) for their kind guidance and praiseworthy inspiration and support for this study.

\section{References}

1. Singh B, Guru SK, Sharma R, Bharate SS, Khan IA, et al. (2014) Synthesis and anti-proliferative activities of new derivatives of embelin. Bioorganic Med Chem Lett 24: 4865-4870.

2. Chitra M, Devi CS, Sukumar E (2003) Antibacterial activity of embelin. Fitoterapia 74: 401-403.

3. Afzal M, Gupta G, Kazmi I, Rahman M, Upadhyay G, et al. (2012) Evaluation of anxiolytic activity of embelin isolated from Embelia ribes. Biomedicine \& Aging Pathology 2: 45-47.

4. Kessler RC, McGonagle KA, Zhao S, Nelson CB, Hughes M (1994) Lifetime and 12-month prevalence of DSM-III-R psychiatric disorders in the United States: Results from the National Comorbidity Survey. Arch Gen Psychiatry 51: 8-19.

5. Moffitt TE, Caspi A, Taylor A, Kokaua J, Milne BJ, et al. (2010) How common are common mental disorders? Evidence that lifetime prevalence rates are doubled by prospective versus retrospective ascertainment. Psychol Med 40: 899-909.

6. Mahendran S, Thippeswamy BS, Veerapur VP, Badami S (2011) Anticonvulsant activity of embelin isolated from Embelia ribes. Phytomedicine 18: 186-188.

7. Poole K, Moran N, Bell G, Solomon J, Kendall S, et al. (2000) Patients perspectives on services for epilepsy: A survey of patient satisfaction, preferences and information provision in 2394 people with epilepsy. Seizure 9: 551-558

8. Hosseinzadeh H, Parvardeh S (2004) Anticonvulsant effects of thymoquinone, the major constituent of Nigella sativa seeds, in mice. Phytomedicine 11: 56-64.

9. Gale K (1991) GABA and epilepsy: Basic concepts from preclinical research. Epilepsia 33: S3-12.

10. Shirole RL, Shirole NL, Saraf MN (2015) Embelia ribes ameliorates lipopolysaccharide-induced acute respiratory distress syndrome. J Ethnopharmacol 168: 356-363.

11. Spond J, Chapman R, Fine J, Jones H, Kreutner W, et al. (2001) Comparison of PDE 4 Inhibitors, Rolipram and SB 207499 (Ariflo TM, in a Rat Model of Pulmonary Neutrophilia. Pulm Pharmacol Ther 14: 157-164.

12. Schwartz DA (2001) Does inhalation of endotoxin cause asthma? Am J Respir Crit Care Med 163: 305-306.

13. Ulich TR, Fann MJ, Patterson PH, Williams JH, Del Castillo, et al. (1994) Intratracheal injection of LPS and cytokines. V. LPS induces expression of LIF and LIF inhibits acute inflammation. Am J Physiol Lung Cell Mol Physiol 267: L442-L446.

14. Wheeler AP, Bernard GR (2007) Acute lung injury and the acute respiratory distress syndrome: A clinical review. The Lancet 369: 1553-1564.

15. Esteban A, Frutos-Vivar F, Muriel A, Ferguson ND, Peñuelas O, et al. (2013) Evolution of mortality over time in patients receiving mechanical ventilation. Am J Respir Crit Care Med 188: 220-230.

16. Rubenfeld GD, Caldwell E, Peabody E, Weaver J, Martin DP, et al. (2005) Incidence and outcomes of acute lung injury. $\mathrm{N}$ Engl J Med 353: 1685-1693.

17. Dhadde SB, Nagakannan P, Roopesh M, Kumar SA, Thippeswamy BS, et al. (2016) Effect of embelin against 3-nitropropionic acid-induced Huntington's disease in rats. Biomed Pharmacother 77: 52-58.

18. Leegwater-Kim J, Cha JHJ (2004) The paradigm of Huntington's disease: Therapeutic opportunities in neurodegeneration. NeuroRx 1: 128-138.

19. Phillips W, Shannon KM, Barker RA (2008) The current clinical management of Huntington's disease. Movement Disorders 23: 1491-1504.

20. Reynolds DS, Carter RJ, Morton AJ (1998) Dopamine modulates the susceptibility of striatal neurons to 3-nitropropionic acid in the rat model of Huntington's disease. J Neurosci 18: 10116-10127.

21. Tariq M, Khan HA, Elfaki I, Al Deeb S, Al Moutaery K (2005) Neuroprotective effect of nicotine against 3-nitropropionic acid (3-NP)induced experimental Huntington's disease in rats. Brain Res Bull 67: 161-168.

22. Túnez I, Tasset I, Pérez-De La Cruz V, Santamaría A (2010) 3Nitropropionic acid as a tool to study the mechanisms involved in Huntington's disease: past, present and future. Molecules 15: 878-916.

23. Ahuja M, Bishnoi M, Chopra K, (2008) Protective effect of minocycline, a semi-synthetic second-generation tetracycline against 3-nitropropionic acid (3-NP)-induced neurotoxicity. Toxicology 244: 111-122.

24. Kumar P, Kumar A (2009) Neuroprotective effect of cyclosporine and FK506 against 3-nitropropionic acid induced cognitive dysfunction and glutathione redox in rat: Possible role of nitric oxide. Neuroscience Research 63: 302-314.

25. Kumar P, Padi SS, Naidu PS, Kumar A (2006) Protective effect of antioxidants on 3-nitropropionic acid induced oxidative stress and cognitive impairment. Ann Neurosci 13.

26. Ludolph AC, He F, Spencer PS, Hammerstad J, Sabri M (1991) 3Nitropropionic acid-exogenous animal neurotoxin and possible human striatal toxin. Canadian Journal of Neurological Sciences 18: 492-498.

27. Paykel ES (2006) Depression: Major problem for public health. Epidemiol Psychiatr Sci 15: 4-10.

28. Mahendran S, Badami S, Maithili V (2011) Evaluation of antidiabetic effect of embelin from Embelia ribes in alloxan induced diabetes in rats. Biomedicine \& Preventive Nutrition 1: 25-31. 
29. Bharati DR, Pal R, Kar S, Rekha R, Yamuna TV, et al. (2011) Prevalence and determinants of diabetes mellitus in Puducherry, South India. Journal of Pharmacy and Bioallied Sciences 3: 513.

30. Mohan V, Deepa M, Deepa R, Shanthirani CS, Farooq S, et al. (2006) Secular trends in the prevalence of diabetes and impaired glucose tolerance in urban South India: The Chennai Urban Rural Epidemiology Study (CURES-17). Diabetologia 49: 1175-1178.

31. Mohan V, Mathur P, Deepa R, Deepa M, Shukla DK, et al. (2008) Urban rural differences in prevalence of self-reported diabetes in India-The WHO-ICMR Indian NCD risk factor surveillance. Diabetes Res Clin Pract 80: 159-168.

32. Naik SR, Niture NT, Ansari AA, Shah PD (2013) Anti-diabetic activity of embelin: involvement of cellular inflammatory mediators, oxidative stress and other biomarkers. Phytomedicine 20: 797-804.

33. Deb L, Dutta A (2006) Diabetes mellitus its possible pharmacological evaluation techniques and naturopathy. Int J Green Pharmacy 1: 28.

34. Sicree R, Shaw J, Zimmet P (2006) Prevalence and projections. Diabetes Atlas 3: 16-104.

35. Kumar K, Dhamotharan R, Kulkarni NM, Honnegowda S and Murugesan S, (2011) Embelin ameliorates dextran sodium sulfateinduced colitis in mice. Int Immunopharmacol 11: 724-731.

36. Blumberg RS, Saubermann LJ, Strober W, (1999) Animal models of mucosal inflammation and their relation to human inflammatory bowel disease. Curr Opin Immunol 11: 648-656.

37. Russel MGVM (2000) Changes in the incidence of inflammatory bowel disease: What does it mean? Eur J Intern Med 11: 191-196.

38. Strober W, Fuss IJ, Blumberg RS (2002) The immunology of mucosal models of inflammation1. Annu Rev Immunol 20: 495-549.

39. Fiocchi C (1998) Inflammatory bowel disease: Etiology and pathogenesis. Gastroenterology 115: 182-205.

40. Hendrickson BA, Gokhale R, Cho JH (2002) Clinical aspects and pathophysiology of inflammatory bowel disease. Clin Microbiol Rev 15: 79-94.

41. Ardizzone S,Porro GB (2005) Biologic therapy for inflammatory bowel disease. Drugs 65:2253-2286.

42. Swamy HK, Krishna V, Shankarmurthy K, Rahiman BA, Mankani KL, et al. (2007) Wound healing activity of embelin isolated from the ethanol extract of leaves of Embelia ribes Burm. J Ethnopharmacol 109: 529-534.

43. Morton JJ, Malone MH (1972) Evaluation of vulneray activity by an open wound procedure in rats. Arch Int Pharmacodyn Ther 196: 117

44. Ehrlich HP, Hunt TK (1969) The effects of cortisone and anabolic steroids on the tensile strength of healing wounds. Ann Surg 170: 203.

45. Mohandas S, Sreekumar TR, Prakash V (2013) Anthelmintic activity of vidangadi churna. Asian J Pharm Clin Res 6: 94-95.

46. Bundy DAP (1994) The global burden of intestinal nematode disease. Transactions of the Royal Society of Tropical Medicine and Hygiene 88 259-261.

47. Tagboto S, Townson S (2001) Antiparasitic properties of medicinal plants and other naturally occurring products. Adv Parasitol: 199-295.

48. Sondhi SM, Sahu R, Magan A, Ghosh DK (1994) Anti-Amoebic and anthelmintic evaluation of heterocyclic compounds containing nitrogen and/or sulphur. Indian Drugs-Bombay 31: 317-317.

49. Radhakrishnan N, Gnanamani A (2014) 2, 5-dihydroxy-3-undecyl-1, 4benzoquinone (Embelin)-a second solid gold of India: A review. Int J Pharm Pharm Sci 6: 23-30.

50. Honigberger JM (1852) Thirty-five Years in the East: Adventures, Discoveries, Experiements and Historical Sketches, Relating to the Punjab and Cashmere; in Connection with Medicine, Botany, Pharmacy, Etc. Together with an Original Materia Medica; and a Medical Vocabulary, in Four European and Five Eastern Languages (Vol. 1). H. Baillière.

51. Rahman ARB, Zhang J (2013) Rayada specialty: The forgotten resource of elite features of rice. Rice 6: 41.

52. Prakash V, Mehrotra BN (1987) Anthelmintic plants in traditional remedies in India. Indian J Hist Sci 22: 332-340.
53. Mojumder V, Mishra SD (1990) In vitro studies on toxicity of embelin and its haloderivatives to Meloidogyne incognita juveniles. Curr Nematol 1: $47-48$.

54. Jalalpure SS, Alagawadi KR, Mahajanashetti CS, Shah BN, Singh V, et al. (2007) In vitro anthelmintic property of various seed oils against Pheritima posthuma. Indian J Pharm Sci 69: 158.

55. Chitra M, Devi CS, Sukumar E (2003) Antibacterial activity of embelin. Fitoterapia 74: 401-403.

56. Feresin GE, Tapia A, Sortino M, Zacchino S, de Arias AR, et al. (2003) Bioactive alkyl phenols and embelin from Oxalis erythrorhiza. J Ethnopharmacol 88: 241-247.

57. Rani P, Khullar N (2004) Antimicrobial evaluation of some medicinal plants for their antienteric potential against multidrug resistant Salmonella typhi. Phytother Res 18: 670-673.

58. Tambekar DH, Khante BS, Chandak BR, Titare AS, Boralkar SS, et al. (2009) Screening of antibacterial potentials of some medicinal plants from Melghat forest in India. Afr J Tradit Complement Altern 6:228-232.

59. Rathi SG, Bhaskar VH, Patel PG (2010) Antifungal activity of Embelia ribes plant extracts. Int J Pharm Biol Res 1: 6 .

60. Suthar M, Patel R, Hapani K, Patel A (2009) Screening of Embelia ribes for antifungal activity. Int J Pharma Sci Drug Res 1: 203-206.

61. Radhakrishnan N, Gnanamani A, Mandal AB (2011) A potential antibacterial agent Embelin, a natural benzoquinone extracted from Embelia ribes. Biol Med 3:1-7.

62. Chitra M, Sukumar E, Suja V, Devi CS (1994) Antitumor, antiinflammatory and analgesic property of embelin, a plant product. Chemotherapy 40: 109-113.

63. Nikolovska-Coleska Z, Xu L, Hu Z, Tomita Y, Li P, et al. (2004) Discovery of embelin as a cell-permeable, small-molecular weight inhibitor of XIAP through structure-based computational screening of a traditional herbal medicine three-dimensional structure database. J Med Chem 47: 2430-2440.

64. Dai Y, DeSano J, Qu Y, Tang W, Meng Y, et al. (2011) Natural IAP inhibitor Embelin enhances therapeutic efficacy of ionizing radiation in prostate cancer. Am J Cancer Res 1: 128-143.

65. Sreepriya M, Bali G (2005) Chemopreventive effects of embelin and curcumin against N-nitrosodiethylamine/phenobarbital-induced hepatocarcinogenesis in Wistar rats. Fitoterapia 76: 549-555.

66. Sumino M, Sekine T, Ruangrungsi N, Igarashi k, Ikegami F (2002) Ardisiphenols and other antioxidant principles from the fruits of Ardisia colorata. Chem Pharm Bull (Tokyo) 50: 1484-1487.

67. Joshi R, Kamat JP, Mukherjee T (2007) Free radical scavenging reactions and antioxidant activity of embelin: Biochemical and pulse radiolytic studies. Chem Biol Interact 167: 125-134.

68. Surveswaran S, Zhong Cai Y, Corke H, Mei Sun (2007) Systematic evaluation of natural phenolic antioxidants from 133 Indian medicinal plants. Food Chem 102: 938-953.

69. Uma B, Nazam Ansari M, Islam F, Tripathi CD (2008) The effect of aqueous extract of Embelia ribes Burm on serum homocysteine, lipids and oxidative enzymes in methionine induced hyperhomocysteinemia. Ind J Pharmacol 40: 152-157.

70. Venkateshwar rao, Sateesh kumar G, Mujahidul Islam, Mansour SE (2008) Folk medicines for anticancer therapy-a current status. Cancer Thera 6: 913-922.

71. Singh D, Singh R, Singh P, Gupta RS (2009) Effects of embelin on lipid peroxidation and free radical scavenging activity against liver damage in rats. Basic Clin Pharmacol Toxicol 105: 243-248.

72. Radhakrishnan N, Rajendra Prasad N, Gnanamani A, Mandal AB (2012) Inhibition of UVB-induced oxidative damage and apoptotic biochemical changes in human lymphocytes by 2, 5-dihydroxy-3-undecyl-1, 4benzoquinone (embelin). Int J Radiat Biol 88: 575-582.

73. 75 Kocak C, Kocak FE, Akcilar R, Isiklar OO, Kocak H, et al.(2016) Molecular and biochemical evidence on the protective effects of embelin and carnosic acid in isoproterenol-induced acute myocardial injury in rats. Life Sci 147: 15-23. 
Citation: Kumar S, Deshmukh R (2017) Embelin as a Potential Drug Molecule: A Review. J Pharmacogn Nat Prod 3: 144. doi: 10.4172/2472-0992.1000144

Page 7 of 7

74. Reddy K, Khaliq A, Henning RJ (2015) Recent advances in the diagnosis and treatment of acute myocardial infarction. World J Cardiol 7: 243.

75. Ambrose JA, Singh M (2015) Pathophysiology of coronary artery disease leading to acute coronary syndromes. F1000 Prime Rep 7: 08.

76. Frank A, Bonney M, Bonney S, Weitzel L, Koeppen M, et al. (2012) Myocardial ischemia reperfusion injury. In: Seminars in Cardiothoracic and Vascular Anesthesia 16:123-132.

77. Hausenloy DJ, Yellon DM (2013) myocardial ischemia-reperfusion injury: A neglected therapeutic target. J Clin Invest 123: 92-100.
78. Burke AP, Virmani R (2007) Pathophysiology of acute myocardial infarction. Med Clin North Am 91: 553-572.

79. Purandare TV, Kholkute SD, Gurjar A, Joshi UM, Dattatreyamurty B, et al. (1979) Semen analysis \& hormonal levels in bonnet macaques administered Embelia ribes berries, an indigenous plant having contraceptive activity. Indian J Exp Biol 17: 935-936. 